\title{
EL CARRO Y SU FUNCIÓN SOCIAL DURANTE EL BRONCE \\ FINAL Y EL ORIENTALIZANTE EN EL SUROESTE DE LA PENÎNSULA IBÉRICA: UNA REVISIÓN NECESARIA ${ }^{1}$
}

\author{
THE CHARIOT AND ITS SOCIAL FUNCTION IN THE LATE BRONZE AGE AND \\ ORIENTALISING PERIOD IN THE IBERIAN SOUTH-WEST: A REVIEW
}

\author{
por
}

JESÚS JOYA GUERRERO

\begin{abstract}
"Sin esfuerzo, has creado los ríos que deben desembocar en el mar, semejante a los carros que te llevan al sacrificio; los has creado como aquellos que desean ir al combate construyen sus carros."

Himnos del Rigveda, Libro I, Himno CXXX, Indra. (Griffith 1973 en Renfrew 1990: 151)
\end{abstract}

RESUMEN Desarrollo en este trabajo la hipótesis de que los carros protohistóricos constituyeron objetos de prestigio y atributos de honor para las aristocracias guerreras en proceso de consolidación como clases dirigentes y que, como tales, el contexto arqueológico de estos vehículos debería estar constituido por objetos o símbolos asociados a una determinada mentalidad, de tipo elitista, propia de los grupos sociales dominantes. A partir de aquí repaso las fuentes arqueológicas que tradicionalmente han servido a los autores para defender la existencia de carros en el suroeste peninsular en momentos anteriores y coetáneos a la colonización fenicia, rechazándose por improcedentes unas (pinturas rupestres de Peñalsordo) y manteniéndose entre interrogantes otras (estelas decoradas del suroeste).

ABSTRACT I develop in this work the hypothesis that the protohistoric chariots constituted objects of prestige and attributes of honour for the warrior aristocracies in their process of consolidation as ruling classes, and as such, the archeologic context of these vehicles should be constituted by objects or symbols associated to a determined mentality of elitist type, characteristic of the dominant social groups. Starting from this point I go over the archeologic sources that traditionally have served to the authors in defense of the existence of chariots in the peninsular southwest before and during the phoenician colonization, rejecting as unsuitable some -the Peñalsordo rupestrian paintings- and maintaining some others in question marks -the decorated steles of the southwest-.

1. Seguiremos aquí la secuencia cronológica tradicional que se ha aplicado a la protohistoria del Valle del Guadalquivir: el Bronce Final supone un momento inmediatamente anterior a los primeros contactos con el Mediterráneo oriental mientras que el Orientalizante constituye el periodo en el que éstos se desarrollan (la frontera entre ambos se situaría a mediados del siglo VIII a. C.). 


\section{INTRODUCCIÓN}

El carro durante la Antigüedad constituyó fundamentalmente un objeto de guerra y prestigio ${ }^{2} . \mathrm{Si}$ exceptuamos el caso de los carros dedicados a las faenas agrícolas que, probablemente, deberíamos situar más tardíamente en el tiempo, el resto, principalmente el carro ligero de un sólo eje tirado por caballos -con una función presumiblemente bélica-, constituyó uno de los bienes más preciados para los "señores de la guerra" (léase aristocracia) dentro de unas sociedades inmersas en procesos de formación y consolidación estatal $^{3}$. El guerrero que acudía a la batalla conduciendo un carro contaba con una enorme ventaja sobre el infante a la hora del combate: a una mayor movilidad se sumaba una plataforma inmejorable para el lanzamiento de proyectiles y la supervisión de las maniobras militares ${ }^{4}$. Durante el Bronce Final y los primeros años de la Edad del Hierro los carros decidieron en gran medida la suerte de las batallas. Es por ello que se convirtieron en uno de los elementos más representativos de la clase dirigente, atributo de su liderazgo social y connotación de la ideología agonística que la definía ${ }^{5}$.

Sin embargo, el ideal heroico del "conductor de carros" no estaba abierto a toda la sociedad, y solamente los "mejores" y los "buenos" podían aspirar a alcanzarlo. Y es que procurarse un carro para la guerra (amén de los animales que lo tiraban) solamente estaba al alcance de los más ricos. De esta manera, además de un elemento de supremacía en la guerra, el carro pasó a constituir el indicativo de un determinado grupo social, así como el símbolo de una mentalidad exclusiva ligada a esta élite.

2. Ello se debe, entendemos nosotros, a su estrecha ligazón en origen con el mundo del guerrero, figura paradigmática en el seno de las sociedades antiguas (Lincoln 1991) pues es el personaje que protege (y somete) a su comunidad, siendo además, en muchas de ellas, el único con derecho a portar armas. De ahí que éstas se conviertan en referente obligado para mostrar el status. Es desde este punto de vista que definimos el carro como un elemento de prestigio social, connotación de una élite marcial y sólo de ésta: un documento tan antiguo como el "Estandarte de Ur" (3000-2340 a. C.) se nos muestra como ejemplo ideal de esto que proponemos. Este conocido objeto tiene dos caras en las que se disponen bandas con escenas. En el anverso se nos representa una "hazaña" militar en la que los guerreros victoriosos tras la batalla avanzan conduciendo sus carros -de los que sobresalen las jabalinas- sobre los cadáveres de los vencidos. En el registro superior la figura del carro se asocia directamente a la del rey (Frankfort 1992: 78). En el reverso se hace referencia a actividades domésticas como la producción de alimentos y probablemente el transporte de presentes agrícolas y ganaderos como ofrendas al monarca que, de nuevo en el registro superior, parece conmemorar la "hazaña" anterior. El transporte de animales y demás productos se hace manualmente, y el carro, que podría haber resultado de utilidad en este contexto, se encuentra del todo ausente -lo que contrasta con la escena de la otra cara-. Si tal y como señala Redman, el estandarte informa acerca de los comportamientos sociales aceptables dentro de la comunidad, debemos entender que los carros son componéntes propios y característicos de una casta militar, siendo su uso desconocido para el pueblo llano (Redman 1990:384).

3. El caballo no era un animal apropiado para el tiro de carros pesados de cuatro ruedas (Keegan 1995: 201) como el que aparece tirado por onagros en el Estandarte de Ur (que debió tener una escasa utilidad en campaña). Si se deseaba convertir al carro en un practico vehículo de combate había que aligerar el peso de la caja y de las ruedas con el fin de adaptarlas a las características del caballo, potencialmente más útil para el hombre que el burro, el hemión, el asno o el onagro, especies que carecen de las capacidades genéticas para alcanzar por la cría selectiva una mayor fuerza y rapidez. La principal ventaja que se desprendía del menor peso de la caja y de las ruedas de radios eran la velocidad y maniobrabilidad del vehículo. A partir de los carros pesados y de ruedas macizas se desarrolló el carro de guerra, ligero y de un solo eje, en torno a comienzos del II milenio a. C. (Piggott 1983: 64-84).

4. Keegan señala que un arquero montado en un carro que guardase con respecto a los infantes enemigos una distancia de cien o doscientos metros, podía herir a seis hombres por minuto; diez carros durante diez minutos podían causar más de quinientas bajas (Keegan 1995: 210).

5. Los Himnos del Rigveda, codificados en el siglo XVI d. C. pero que hacen referencia a un período remoto en torno a comienzos del I milenio a. C. hablan mucho de los carros conducidos por los "arya" (más conocidos como arios) durante la practica de la guerra. Igualmente se invocan a diferentes dioses que ayudan a los arios a destruir fortalezas enemigas. Los versos reflejan "una sociedad heroica que se glorificaba en la lucha" (Renfrew 1990:152). 
Las victorias en el campo de batalla tenían su reflejo directo en la esfera civil y social, lo que provocó que la clase de los guerreros en carros se convirtiera en la dirigente política e ideológica de la comunidad. Sus modelos de pensamiento y conducta eran los únicos válidos y honorables, produciéndose una extensión de los mismos (de grado o por fuerza) al resto de la masa poblacional, sin duda, con unos ideales más humildes $y$, en todo caso, "peores".

Se trataba, por ejemplo, del esquema tradicional que, en el seno de las sociedades indoeuropeas, contraponía al guerrero y al hombre de aldea. Así, en el mundo hitita, los mandos militares junto con los combatientes que estaban bajo sus ordenes formaban el pankus, asamblea que representaba a la comunidad hitita, es decir, que agrupaba al conjunto de los guerreros con exclusión del resto del pueblo (Vernant 1982: 194).

Así pues un presupuesto nos aparece claro: debemos ligar la existencia del carro (y en esto la Península Ibérica no constituye una excepción) con una élite social. Esta premisa me lleva a plantear mi primera hipótesis: las representaciones figuradas de carros (en pinturas, estelas, maquetas...) así como el hallazgo arqueológico de los mismos (o de alguna de sus partes componentes) debería de ir acompañado del descubrimiento de otros objetos de prestigio asociados a dicha élite aristocrática. Por tanto, el contexto de los carros debe ser suntuoso (Tumbas Reales de Ur, tholoi aqueas), o bien representar las pautas e ideales de un determinado esquema mental (estelas decoradas del suroeste peninsular, necrópolis íberas -en las primeras aparecen armas y otros objetos relacionados con el arreglo corporal del guerrero; en las segundas, además de esto, se han encontrado cráteras y vasos griegos). A tenor de ello, no es comprensible la aparición de vehículos con ruedas fuera de estos marcos, aún cuando se pudiera tratar de representaciones-de carros-con un carácter puramente simbólico, tal como ha interpretado Galán con respecto a las figuraciones que, de los mismos, aparecen en las estelas de la Península Ibérica (Galán 1993).

Como objeto de prestigio y poder, el carro fue utilizado en diferentes regiones como parte del ajuar funerario y, probablemente, fue el medio más utilizado para transportar el cadáver hasta la tumba (FernándezMiranda y Olmos 1986; Quesada 1997). La asociación del difunto al carro podría ser prueba del vínculo post mortem que los unía, lo que vendría a significar que el muerto mantendría en el allende el status social que había detentado en vida. A este respecto, el vehículo, además de una seña de identidad, pudo haberse ligado mentalmente con la idea de la muerte como un tránsito al más allá; un paso o cambio de estado que el guerrero realizaría, de acuerdo a su mentalidad heroica, de forma gloriosa: a las riendas de su carro. En esto se han apoyado algunos autores para defender el carácter funerario de las estelas peninsulares (Bendala 1977; Fernández-Miranda y Olmos 1986).

En la Península Ibérica, los hallazgos de carros están relacionados con enterramientos, como es el caso de los encontrados en las necrópolis íberas de los siglos V-IV a. C. Se ha propuesto que estos usos funerarios dados a los carros podrían haber constituido la evolución de unas prácticas ya conocidas y realizadas en Extremadura y Andalucía occidental durante el Bronce Final y primeros años de la Edad del Hierro, por ejemplo en las estelas y en la necrópolis de La Joya (Fernández-Miranda y Olmos 1986: 159).

Por otro lado, la presencia de carros en una región evidencia la existencia de un artesanado muy especializado de carácter local (producción propia) o foráneo (transacciones comerciales), pero indistintamente sujeto a un intercambio de ideas y a unas corrientes mercantiles. Es éste un tema complicado y que se nos escapa debido a la carencia de fuentes y datos que permitan realizar una reconstrucción coherente del fenómeno. Aunque la llegada del carro a la Península Ibérica responde sin lugar a dudas a un proceso de difusión, el problema radica en averiguar a través de quién y por qué vía estos vehículos se expandieron hasta el extremo occidental del Mediterráneo. Y a este respecto, hay casi tantas hipótesis como autores. La mayoría de ellos coincide en afirmar que el carro existente en la Península a comienzos del primer milenio a. C. era más parecido a los que por aquel entonces se utilizaban en el Mediterráneo oriental que a sus homólogos de la Europa central o septentrional (como los ejemplares de la Cultura de Hallstatt). La diferencia fundamental entre aquéllos y éstos reside en que mientras los primeros (casi en su totalidad) presentan un 
sólo eje (dos ruedas), los segundos tienen dos (cuatro ruedas), lo que parece ser suficiente para entrever dos vías diferentes de transmisión (de oriente a occidente) -Fernández-Miranda y Olmos 1986: 132- . Por una lado tendríamos una vía mediterránea vinculada en un primer momento con el mundo micénico y más tarde con las corrientes comerciales fenicias y griegas; por otro, una vía continental o terrestre que no parece penetrar en la Península (donde los carros de cuatro ruedas están casi totalmente ausentes).

Ahora bien, sabido es que en el proceso de la difusión-aculturación la idea aceptada por la comunidad receptora nunca conserva intactas sus características originales sino que sufre un número mayor o menor de transformaciones que responden a las pautas culturales de la sociedad que la asimila. A este respecto la difusión del carro desde Mesopotamia (lugar de invención de la rueda) hacia occidente no tendría por qué haberse dado a través de dos vías diferentes ya que las variaciones en la forma y en el numero de ruedas de los carros podrían haber respondido a procesos endógenos dentro de las culturas que los acogieron. La expansión del carro muy bien podría explicarse mediante la teoría de la "ola en avance", que ya ha sido aplicada a otros procesos como el de la difusión de la agricultura por Ammerman y Cavalli-Sforza (1984: 63-84). Sin embargo, también es cierto que no es suficiente con que el sistema se autoexpanda pues para que se consolide en un nuevo territorio tiene que ser aceptado en el mismo. Por ello en nuestro caso, me parece importante subrayar dos ideas con las que no han contado todos los autores que, hasta la fecha, se han dedicado al estudio de este asunto: a) la emigración de un determinado componente poblacional no reproduce en el nuevo lugar de asentamiento la totalidad de las características propias de la sociedad de origen, sino solamente las de un sector de la comunidad. b) Para que se produzca la aceptación del carro es necesario la existencia de un orden social y de un grado de desarrollo específico (domesticación de animales de tiro, artesanos especializados al servicio de la élite y vías o caminos por los que los vehículos puedan transitar, así como el cuidado y la vigilancia de los mismos). El carro no puede ser asimilado por cualquier sociedad, al menos de forma practica, lo cual no anula su posible utilización como elemento simbólico al servicio de una clase dirigente en proceso de gestación.

Ambas ideas me parecen de crucial interés a la hora de iniciar un estudio serio sobre los primeros carros, y su función social, existentes en nuestra Península.

\section{LAS FUENTES Y SUS PROBLEMAS CRONOLÓGICOS}

Uno de los problemas (tal vez el mayor de todos) que se plantea dentro de este estudio es el de conocer la fecha de introducción del carro en nuestro territorio, así como su desarrollo en el tiempo. Tradicionalmente se ha tendido a considerar a los "carros" representados en las pinturas rupestres de Peñalsordo (Badajoz) como los más antiguos de la Península Ibérica (Almagro Basch 1966; Piggot 1983; Fernández-Miranda y Olmos 1986). Estos autores se han basado para establecer esta afirmación en criterios puramente estilísticos realizando comparaciones iconográficas con otros carros similares grabados o pintados en distintos puntos de Europa o de la propia Península Ibérica. A tenor de su proximidad geográfica y temática (?), así como a su similar tratamiento artístico, Fernández-Miranda y Olmos proponen la posible coetaneidad de las pinturas con las estelas extremeñas, fechándolas en torno al año 900 a. C. (Fernández-Miranda y Olmos 1986: 105-107). Sin embargo, los estudios iconológicos han demostrado que la forma de esquematizar los carros se encuentra muy estandarizada en todo el ámbito mediterráneo, Europa central y septentrional y el Próximo Oriente, incluso en fechas distintas. Así pues, resultaría más correcto desechar las comparaciones iconográficas y centrarnos en el análisis cronológico de las pinturas en sí. El problema está en que la cuestión de la cronología en lo que al Arte Esquemático Rupestre (Peninsular) se refiere, es aún un asunto impreciso. Numerosos autores lo han investigado llegando a conclusiones cronológicas muy diferentes. Ello podría ser indicativo de la larga duración en el tiempo de estas pinturas, que abarcarían por lo tanto sucesivos periodos culturales 
(entre el Epipaleolítico y el Bronce Final). Teniendo en cuenta este argumento y que en el actual estado de conocimiento es del todo imposible fijar unas fechas para el origen y el final de este fenómeno, resulta muy escabroso intentar establecer una cronología para los supuestos carros aparecidos en Peñalsordo. Acosta intenta salvar esta cuestión recurriendo, una vez más, a la comparación de las pinturas con los grabados de las estelas y situando los dibujos de los vehículos en las últimas series cromáticas dentro de los abrigos en los que se encuentran (Acosta 1968: 102-104). Este último argumento debe ser tomado como simple suposición, pues no se aportan datos o pruebas de carácter sustentorio.

Siguiendo la línea tradicional, el siguiente grupo de fuentes en el tiempo estaría constituido por las representaciones grabadas de las estelas del suroeste peninsular, habiendo aparecido en gran numero de ellas figuraciones de carros. Sin embargo, las cronologías propuestas por los diversos autores que se han dedicado al estudio de las estelas presentan notables divergencias. La metodología tradicional para fecharlas ha consistido en el análisis individual y pormenorizado de cada uno de los elementos en ellas grabados con el objeto de establecer paralelismos con otras regiones, y a partir de ahí montar teorías de carácter difusionista que han variado dependiendo de la tendencia investigadora imperante en esos momentos (Galán 1993: 15-22). Este tipo de estudios era válido desde la postura tradicional con la que siempre se ha abordado el análisis de las estelas, y que veía en éstas marcadores de tumbas y en sus representaciones la sustitución de un ajuar funerario. Este pensamiento llevó a la concepción de que en las estelas aparecían conjuntos cerrados de objetos que habían circulado a la vez, y que por tanto constituían el reflejo de un período histórico determinado. Esto ha significado que todos los autores que han abordado el tema hayan enfatizado las relaciones sincrónicas frente a las diacrónicas. La identificación de los grabados con objetos de prestigio ha llevado, igualmente, a relegar la posible valoración simbólica de los mismos como marcadores de la riqueza y el territorio en el interior de unas sociedades en las que se iniciaba la fijación de los niveles de autoridad. En este sentido, tal como interpreta Galán, los objetos elevados a la categoría de elementos simbólicos pueden tener una vida más larga que sus referentes reales, constituyendo esto un factor de distorsión de las cronologías basadas en la simple comparación de los componentes formales (Galán 1993).

A tenor de las interpretaciones tradicionales los carros de las estelas han sido situados bajo diferentes cronologías dependiendo de la cultura foránea con la que se los haya relacionado:

Bendala contempla en los carros de nuestras estelas claras analogías con los representados en los grandes vasos griegos del Geométrico pleno (siglos VIII-VII a. C. -Ben-dala 1977-). Por su parte Almagro-Gorbea ve en los carros un elemento bastante antiguo dentro de las estelas, relacionándolos con un momento protocolonial (en relación al Mediterráneo oriental) que habría que fechar entre los siglos IX y VIII a. C., pero con orígenes desde finales del II milenio a. C. (Almagro-Gorbea 1977). Almagro Basch ve en nuestros vehículos a los carros funerarios de la Cultura Hallstáttica, situando su llegada a la Península en torno al 800 a. C., fecha, según él, de las invasiones célticas (Almagro Basch 1966). Finalmente, los partidarios de un origen Atlántico de las estelas fechan sus elementos grabados entre los siglos XI y VIII a. C. (Coffyn 1985; Barceló 1989).

Desde un punto de vista ecléctico, y teniendo en cuenta estos datos, podríamos fechar la aparición de los primeros carros peninsulares entre los siglos XI y VII a. C. Sin embargo, creo que es muy importante, llegados a este punto, diferenciar a los vehículos grabados en las estelas de Extremadura y Andalucía occidental de la existencia real de los mismos. Una cosa no lleva a la otra y la presencia de representaciones no prueba el conocimiento y la utilización directa de las correspondientes realidades materiales: un símbolo no indica forzosamente una realidad presente dentro de una comunidad, sino que puede, por ejemplo, haberse tomado prestado de otros grupos vecinos que lo utilizaban como elemento de status y poder. Así pues, los grabados de carros en las estelas del suroeste del Bronce Final no tienen por qué responder a referentes reales, o lo 
que es lo mismo, a estas alturas de nuestro estudio aún carecemos de pruebas materiales directas asociadas a la existencia de carros en nuestro territorio durante el Bronce Reciente ${ }^{6}$.

La solución a nuestras dudas nos la aporta la Arqueología. La excavación sistemática llevada a cabo en la necrópolis de La Joya (Huelva) sacó a la luz en la tumba 17 y 18, junto a otros objetos de ajuar de carácter excepcional, los restos de dos carros de los que solamente se conservaban sus elementos metálicos (Garrido y Orta 1978). Los investigadores situaron la cronología del yacimiento, a tenor de los elementos aparecidos, entre finales del siglo VIII y la segunda mitad del siglo VI a. C. Fernández-Miranda y Olmos fechan el carro dentro del último cuarto del siglo VII a. C. (Fernández-Miranda y Olmos 1986). No encuentro motivos para dudar de estas dataciones, por lo que parece segura la existencia del carro en el suroeste peninsular en estos momentos, dentro ya del Orientalizante. Nótese, sin embargo, que sólo poseemos una fecha, o mejor, un paréntesis temporal, a partir del cual la presencia de carros es incuestionable; pero desconocemos, no obstante, si con anterioridad se había producido la extensión del vehículo a la Península Ibérica.

Por otra parte, el hallazgo de pasarriendas en la Ría de Huelva, dentro de un contexto selectivamente asociado a elementos identificativos de rango social elevado, también parece demostrar la existencia de carros. Marisa Ruiz-Gálvez, basándose en dataciones calibradas, ha establecido la cronología de la Ría de Huelva en el marco del Bronce Final entre los siglos XIII y VIII a. C. (Ruiz-Gálvez 1995). Esto puede elevar un tanto la fecha de la que antes hablábamos, pero tampoco existen motivos para pensar que los pasarriendas encontrados se remonten mucho en el tiempo. De esta manera podríamos situar el siglo VIII a. C. como frontera temporal a partir de la cual poseemos testimonios directos de que hay carros en suroeste peninsular. Con anterioridad su presencia es presumible pero no confirmable, al menos, con los datos de que ahora disponemos.

\section{LOS “CARROS” PINTADOS DE PEÑALSORDO}

La argumentación de que las pinturas de los abrigos $5^{\circ}$ y $10^{\circ}$ de los Buitres de Peñalsordo (Badajoz) representan carros se trata, a mi juicio, de una suposición que ha sido aceptada muy acríticamente y con demasiada facilidad. Tanto Acosta como Fernández-Miranda y Olmos no dudan de que son vehículos con ruedas ( $y$ sin ellas -narrias-) lo que aparecen en estas figuras, y es ésta una idea que se ha mantenido arraigada a través de los años.

Personalmente dudo de esta interpretación y no veo en la asociación de signos soliformes y escalariformes a los carros de los que hablan los investigadores. Hay argumentos suficientes para rebatir la hipótesis tradicional:

a) Partiendo de nuestra primera hipótesis hay que decir que estos "carros" no se encuentran en un contexto adecuado de acuerdo a las argumentaciones que arriba he sostenido (asociados a elementos simbólicos o suntuarios -relacionados con una determinada mentalidad-). La figuración de los mismos en abrigos de rocas no parece, en principio, la manifestación de un ideal aristocrático. Igualmente, no están asociados con otros objetos de prestigio (como armas -a excepción de una supuesta hacha interpretada por Breuil y de un puñal, que sí parece más claro, ambos en el abrigo $10^{\circ}-$ ), es más, ni siquiera aparecen relacionados con figuras humanas. Esto los aparta de las estelas, donde los carros grabados aparecen siempre -ya sean de carácter simbólico o real- como representativos de una determinada élite social y su ideología. En Peñalsordo está ausente todo este trasfondo, y al contrario de las estelas, los abrigos en los que estas pinturas

6. Soy consciente de que este argumento es muy peligroso porque si dudamos de la existencia de todos los objetos representados en las estelas nos podemos quedar sin nada; sin embargo hay que tener en cuenta lo estandarizados que se encuentran los grabados de carros, siempre a vista de pájaro y con los mismos elementos, lo que puede sugerir la existencia de un modelo original que se adoptó por parte de comunidades que desconocían el referente real. 
se encuentran aparecen como un ámbito, a priori, accesible a todos, independientemente de su rango social. $\mathrm{Si}$ el carro se liga a una aristocracia, aquí no parece existir ninguna, por lo que la existencia de vehículos con ruedas, al menos a tenor del esquema mental que venimos sosteniendo, no parece posible.

b) En ninguna figuración aparecen representados los animales de tiro. Si entendemos el carro como un conjunto de elementos no se comprende la ausencia de aquellos que constituyen su fuerza motriz. Puede argumentarse que se pintaron figuras que representaban carros desenganchados, pero esto no explica el que otros elementos característicos, como pueden ser los ejes de las ruedas, las lanzas o los yugos, y los asideros no aparezcan nunca reflejados.

c) En algunas de las representaciones existe un desequilibrio entre el tamaño de la "caja" (signo escalariforme) y el numero de "ruedas" (dos signos soliformes), por lo que no parece lógico que respondieran a modelos reales que, de haber existido, hubiesen presentado desproporciones en sus formas que se hacen difíciles de aceptar; tanto más cuando también aparecen pintados "carros con cuatro ruedas" (signo escalariforme y cuatro signos soliformes) que suponen modelos más coherentes. No se trata, pienso yo, como se ha propuesto (Fernández-Miranda y Olmos 1986: 105) de dos tipos de vehículos concebidos con distintas finalidades de empleo, sino de conjuntos de símbolos cuyo verdadero significado se nos escapa.

Aunque no rechazo totalmente la posibilidad de que las pinturas de Peñalsordo hagan alusión a carros, espero que las argumentaciones anteriores sirvan como contraste a las suposiciones acríticas y constituyan un punto de referencia para abordar el tema desde un renovado punto de vista. Podríamos decir que es posible que las pinturas representen vehículos (aunque personalmente tiendo a considerar que no es así) pero que carecemos de pruebas que lo confirmen. De ser carros, éstos se encontrarían inmersos dentro de unos contextos peculiares y unos esquemas culturales propios, diferentes, desde luego, de los que nos han servido a nosotros para argumentar y montar la base teórica por la que nos hemos guiado.

\section{LOS CARROS GRABADOS EN LAS ESTELAS DEL SUROESTE PENINSULAR}

Con respecto a los mismos no hay que dudar de que se trata de figuraciones que representan verdaderos carros. La tendencia habitual por parte de los investigadores ha sido la de buscar a éstos paralelismos iconográficos y materiales en otros lugares del Mediterráneo y del continente europeo, bajo el presupuesto de que las estelas pertenecían a un determinado periodo histórico claramente demarcable. Los carros en ellas representados vendrían a constituir un elemento indicativo del grupo social al que pertenecía el difunto enterrado en la tumba, de la cual la estela constituía su marcador. Era, por tanto, un objeto de prestigio que acompañaba a su poseedor hasta el más allá. Con estos fundamentos se ha tratado tradicionalmente a los elementos grabados en las estelas como conjuntos cerrados, pertenecientes a unas fechas concretas, y sincrónicos entre sí (aunque algunos autores, como Almagro-Gorbea, han realizado sistematizaciones intentando aclarar la evolución de los motivos representados). El carro se ha visto como un artefacto de origen foráneo llegado a la Península a través de pueblos invasores o corrientes comerciales y, dentro de las estelas, se ha incidido en su posible simbolismo funerario (Almagro Basch 1966; Bendala 1977; Almagro-Gorbea 1977).

Si atendemos a los diferentes orígenes planteados para la llegada del carro a nuestro territorio obtenemos un mosaico de suposiciones (basadas en paralelismos estilísticos e iconográficos) que han ido variando por las tendencias ideológicas del momento:

Almagro Basch (1966) identificaba los vehículos de las estelas con los carros de la Cultura de Hallstatt, otorgándoles un origen celta o indoeuropeo. A esto contribuyó en gran medida su equivocación con respecto al número de ruedas de los carros grabados, que él situó en cuatro. Almagro Basch confundió las formas curvadas de la parte posterior de la caja con ruedas, cuando en realidad se trata de asideros. Los carros sólo 
tienen dos ruedas (a excepción del aparecido en Solana de Cabañas que sí presenta doble eje ${ }^{7}$ ) lo que los aleja de una ligazón cultural con el centro de Europa. Hoy en día, su explicación invasionista no se sostiene ${ }^{8}$, pero no hay que negar por completo la posibilidad de que algunos carros (los menos y excepcionales -de cuatro ruedas-) del suroeste peninsular se hubiesen inspirado en modelos hallstáticos. A este respecto hay que subrayar lo que en la introducción de este artículo se comentaba en relación a los procesos de difusión-aculturación: una sociedad que adopta de otra un elemento (ya sea ideológico o material) siempre acaba por transformarlo en alguna de sus características (en un intento de adaptarlo a su propia cultura). Así pues, los influjos de la Europa central y septentrional, en lo que a los carros peninsulares (aparecidos en las estelas) se refiere, pudieron ser posibles.

Con el descubrimiento, en los años setenta, de los asentamientos coloniales fenicios del sur peninsular, se produjo un cambio en lo que a las tendencias investigadoras se refiere. Así, Almagro-Gorbea (1977) relaciona los vehículos grabados con los carros mediterráneos, especialmente con los del periodo orientalizante, de Chipre o de Etruria, y con el ejemplar hallado en la tumba 17 de la necrópolis de La Joya en Huelva. Existía, según él, una continuidad cultural entre las estelas y este enterramiento (Almagro-Gorbea 1977: 185). Hay que reseñar sin embargo, que los supuestos ajuares funerarios grabados en las estelas y el encontrado en dicho sepulcro difieren notablemente. Además del carro, sólo presentan en común los espejos (que aún así no están presentes en todas las estelas), por lo que la relación expresada por Almagro-Gorbea no se contempla. Otros autores (Fernández-Miranda y Olmos 1986) han señalado que probablemente el carro enterrado en esta tumba no se tratase ya de un elemento guerrero (como lo eran los de las estelas) sino de un atributo indicativo de la riqueza material, lo que parecería más lógico en el seno de una sociedad que, como la de la Huelva de entonces, era de un marcado carácter mercantil y se había enriquecido con el comercio de los metales. Dicho de otro modo: los "príncipes guerreros" que antaño se habían hecho enterrar con sus armas se convirtieron, con el transcurso del tiempo y la sustitución del concepto de prestigio por el de riqueza, en "príncipes mercaderes" que gustaban de ajuares funerarios de carácter, no ya bélico, sino suntuario (a este respecto, el caso de la tumba 17 de la necrópolis de La Joya constituye un ejemplo excepcional).

Bendala (1977) paraleliza los vehículos de las estelas con los del Geométrico griego otorgándoles un significado de carácter funerario. A este respecto, la escena representada en la estela de Ategua (Córdoba) aparece como paradigmática. En su atractiva lectura Bendala establece similitudes formales entre los elementos grabados de dicha estela y las escenas de próthesis del mundo geométrico griego. Fernández-Miranda y Olmos (1986) señalan que en Ategua el carro y el varón se asocian directamente, pues éste agarra uno de los asideros de la caja, detalle que ellos insinúan, sin atreverse a afirmarlo, podría estar relacionado con la marcha del guerrero en el instante en que éste monta en su vehículo, tal y como ocurre en las representaciones griegas de los siglos VII y VI a. C. para expresar la partida funeraria (Fernández-Miranda y Olmos 1986: 160). En esta línea interpretativa los autores mencionados señalan que podría pensarse en la estela de Ategua como una escena funeraria de carácter doble, donde en la parte superior estaría representado el guerrero con sus atributos y en la inferior la ceremonia fúnebre con el carro y los personajes que formarían la danza o cortejo religioso propio de la exequia. En relación a esto hay que indicar que los carros de las estelas aparecen como un tanto aislados del resto de la representación (por lo general ocupando el lugar inferior de la misma); se podría decir que están aparte. A este respecto, cabría la posibilidad de que los carros constituyesen por sí mismos escenas simplificadas de carácter funerario, en las que los vehículos

7. Quesada interpreta que en este caso el grabador cometió un error que le llevó a repetir eje y ruedas por lo que el vehículo aparece con dos y cuatro respectivamente (Quesada 1997: 157).

8. Hay que señalar que en esto Almagro sólo se limitó a seguir el modelo de cambio cultural imperante en su época, basado en el difusionismo a ultranza. Se hablaba así de las oleadas de invasores celtas que tenían su cuna en la Cultura de Hallstatt, y el propio Childe defendió la llegada a Europa de los indoeuropeos, poseedores de carros de guerra, durante el Bronce Final, identificando a estos grupos de inmigrantes con la cultura de los "Urnenfelder" o Campos de Urnas. 
representasen simbólicamente a la totalidad del cortejo fúnebre. En Ategua se habría desarrollado, excepcionalmente, dicha escena simbólica por razones que desconocemos.

Sin embargo, si el carro constituyó un elemento estructural en los ritos funerarios de los aristócratas que ordenaron erigir estos monumentos, debería estar presente en todas las estelas, y esto no es así porque en la mayoría de ellas no aparece. Frente a esto se puede argumentar que las estelas tienen un desarrollo en el tiempo y los grabados de carros son únicamente un aspecto de un momento determinado, que bien pudiera ser una fase final en la evolución de las mismas, aunque personalmente me resisto a admitir esta idea.

Por otra parte, el hecho de que la máxima concentración de representaciones de carros se sitúe en el Guadiana, una zona con una geografía bastante abrupta donde este tipo de vehículo sería de poca utilidad, nos introduce de lleno en una nueva discusión: la de que los objetos grabados tengan una función puramente simbólica formando parte de un código que, en su tiempo, informó al observador de que penetraba en el territorio de un determinado grupo o clan. Es dentro de este lenguaje simbólico donde un elemento como el carro, con una utilidad real un tanto dudosa, tiene cabida. Y es que, como decíamos al principio, hay que diferenciar los símbolos de sus referentes reales pues aquéllos pueden poseer un significado distinto a éstos. Siempre cabe la posibilidad de la reutilización de las estelas por otros grupos humanos en otro espacio y tiempo, lo cual explicaría la presencia de carros grabados en zonas inadecuadas para su uso. No obstante, y para el caso que nos ocupa, esta reutilización debió de haber sido masiva, lo cual, aunque pudo ocurrir, nos parece poco probable.

Es posible que un objeto como el carro hubiese llegado en muy escasas cantidades al suroeste peninsular merced a un comercio de bienes exóticos y de prestigio que comenzaba a desarrollarse. En el marco de un proceso de territorialización de las élites locales aquellas que poseían vehículos gozaban de un status superior a las demás debido a la ventaja que éste les otorgaba en la guerra. Éstas, ante su inferioridad teórica, desarrollaron mecanismos de emulación basados en el préstamo de los referentes reales y su conversión en elementos simbólicos, dentro de conjuntos iconográficos -las estelas- que muy bien podrían haberse erigido en marcadores territoriales. Ello significaría que las jerarquías propietarias de carros, por el hecho de poseerlos, tendrían menos necesidad de representarlos en los grabados, pues gozaban de su uso efectivo, a la vista de todos, indicativo de su fuerza y poder. Por el contrario, los grupos aristocráticos que, bien por encontrarse ajenos a las rutas comerciales o por estar inmersos en procesos de gestión y consolidación, carecían de estos vehículos, fueron los que en mayor número recurrieron a su figuración simbólica, en un intento de apropiarse su valor ideológico (y puede que también en un intento por intimidar a posibles enemigos haciéndoles creer que poseían armas tan mortíferas como el carro ligero de guerra). Se buscaba así una extensión del prestigio contenido en el objeto a su imagen grabada; ésta se convirtió en un elemento sustitutivo de aquél, y en la medida que suponía un paralelismo se encontraba henchida con el prestigio del referente real, por lo que pasó a ser, por sí misma, un indicativo del status social.

Esta hipótesis podría explicar por qué la mayoría de los carros aparecen en estelas de Extremadura, región ésta, a priori, más atrasada que la del Valle del Guadalquivir, por encontrarse más alejada de la costa, zona tradicional de intercambio de productos e ideas con otros pueblos del Mediterráneo. No obstante, y para ser justos, no hay que pasar por alto el papel estratégico que las tierras extremeñas pudieron haber desempeñado dentro de un comercio entre el mundo atlántico y el meditẹráneo, lo cual haría replantearnos nuestra exposición.

De lo que no hay dudas es de la clara función simbólica de los carros dentro de las estelas. Sean éstas de carácter funerario o espacial, o de ambos a la vez, son indicativas de la existencia de una casta social: la de los guerreros, cuyo principal cometido debemos suponer que sería la realización de correrías en busca de ganado, pues éste constituía la medida de la riqueza (Lincoln 1991). Tal es así que algún autor ha relacionado los cascos de cuernos, con los que aparecen tocados algunas de las figuras humanas de las estelas, con una manifestación de status exclusiva de la aristocracia, en el interior de unas sociedades que consideraban 
JESÚS JOYA GUERRERO

la ganadería de bóvidos la actividad económica más prestigiosa (Padilla 1994). Los conflictos entre unos grupos y otros por la posesión del ganado, presumiblemente debieron provocar un proceso de territorialización y sedentarización que dio lugar a una fijación de los niveles de prestigio y autoridad, dentro de la cual la figura del carro, tanto real como simbólica, tuvo una importancia determinante.

\section{EL CARRO DE LA TUMBA 17 EN LA NECRÓPOLIS DE LA JOYA (HUELVA)}

Los únicos restos arqueológicos en lo que a los primeros carros de la Península Ibérica se refiere proceden de este lugar. Partes de estos vehículos fueron halladas en las tumbas 17 y 18, pero con muchos más elementos, el de la primera tiene una importancia crucial. Su origen ha planteado sugestivos interrogantes. La costumbre de depositar carros en tumbas como parte del ajuar funerario se documenta en Centroeuropa y el Mediterráneo a partir de la Edad del Bronce. La existencia de carros nos indica el poder y el carácter aristocrático de la sociedad que sepultó a sus muertos en la necrópolis de La Joya ${ }^{9}$. Habitualmente se ha tendido a buscar, y no sólo por los restos de los carros, similitudes entre ésta y la que en Salamis excavó Karageorghis. Garrido y Orta (1978: 199-211) han señalado que los vehículos encontrados en ambas presentan una clara inspiración orientalizante que ellos relacionan con importaciones a través del comercio fenicio. Fernández-Miranda y Olmos (1986: 135) se muestran de acuerdo con esta hipótesis y además establecen un nuevo paralelismo con los carros del mundo etrusco como los de las tumbas Regolini-Galasi, San Mariano, Monteleone di Spoleto, Praenase y Chiusi (todas ellas fechadas en el siglo VII a. C.). Bendala (1977: 200) por su parte, incide en la relación de nuestra necrópolis con la chipriota de Salamis, lo que asocia con una colonización de signo grecochipriota que sería la base de la cultura de Tartessos. Bendala diferencia dos zonas en la costa andaluza: por un lado la oriental $\multimap$ mediterránea- controlada por los fenicios; por otro, la occidental $\longrightarrow 0$ atlántica- que constituiría el dominio de los comerciantes griegos (Bendala 1977: 202-203). Así pues, los carros de La Joya responderían a prototipos egeos más que semitas.

Dejando aparte que las investigaciones arqueológicas no constatan la presencia de griegos en este extremo occidental con anterioridad al siglo VII a. C. ${ }^{10}$, somos de la opinión de que los presupuestos de los que parte Bendala, al menos en este artículo, en lo que a las relaciones comerciales se refiere, pueden ser discutibles. El autor, siguiendo la historiografía tradicional que incidía en el enfrentamiento greco-fenicio estableciendo respectivas áreas de control de carácter exclusivo, supone una división de la costa andaluza en dos compartimentos estancos a los que los comerciantes del "bando contrario" no tenían acceso (pues eran enemigos acérrimos).

9. Tal y como señala Aubet con respecto a la empresa colonial fenicia "el comercio de la plata benefició igualmente a un sector de la población tartésica de Huelva, especialmente a sus jefes y régulos locales". Esto motivó que durante el siglo VII a. C. aumentaran las desigualdades socioeconómicas en el interior de las comunidades indígenas (Aubet 1994: 246).

10. Con anterioridad al desarrollo del comercio foceo sólo se han hallado hasta la fecha un fragmento de cerámica geométrica griega en Huelva fechado por Fernández Jurado en 760-730 a. C., dos vasos eubeo-cicládicos en el fondo de cabaña del Carambolo (de finales del siglo VIII o principios del VII a. C.) y un casco corintio sumergido en el río Guadalete (fechado en las primeras décadas del siglo VII a. C.). Tanto aquél como éstos se explican desde el comercio fenicio, no siendo achacables al griego (Amores 1993: 167; Olmos 1989: 500-501). 
Hoy día, esta concepción parece ya superada ${ }^{11}$. Hay que tener en cuenta que el comercio en la Antiguiedad era una actividad de carácter sagrado porque en una época como ésta, de constantes peligros, requería de una garantía. Y esta garantía era la religión. Los comerciantes de diferentes nacionalidades se amparaban bajo la protección de una divinidad de carácter sincrético en un territorio sagrado y por tanto inviolable (en el que no se podía derramar sangre). El mecanismo jurídico que regulaba el comercio era su propia sacralidad. Estamos pues ante un mundo de acuerdos y lugares comunes en los que comerciar (puertos de comercio).

El buscar, por tanto, influencias específicas para los carros encontrados en La Joya puede constituir un grave error, y más aún hacerlas extensivas a todos los posibles vehículos que, durante esta época (fines del siglo VIII-segunda mitad del siglo VIa. C.) circularon por la región, ya que habría que suponer la existencia de diferentes clases de carros (aunque con características similares) debido a procedencias distintas, tanto en lo que respecta a las influencias como a los vehículos en sí, que fueron importados desde el exterior.

Hay que pensar también en la existencia de un artesanado local especializado que cubriría parte de la demanda que, de carruajes, tenía la aristocracia. Los fenómenos de contacto cultural y comercial a lo largo de todo el Mediterráneo a partir del siglo VIII a. C. hicieron posible una serie de relaciones "coloniales" que se plasmaron en la aparición de piezas orientales (chipriotas, minorasiáticas, levantinas y egipcias) en algunos ambientes del Mediterráneo occidental, en concreto los mundos etrusco, suritálico y tartésico. El suntuoso ajuar de la tumba 17 constituye un buen ejemplo de ello.

\section{BIBLIOGRAFÍA}

ACOSTA, P. (1968): La pintura rupestre esquemática en España. Salamanca, Universitas Studii Salamantini. ALMAGRO BASCH, M. (1966): Las estelas decoradas del suroeste peninsular. (B.P.H. VIII). Madrid, Ministerio de Cultura.

(1979): "Los origenes de la toréutica ibérica", Trabajos de Prehistoria 36:173-198.

ALMAGRO-GORBEA, M. (1977): El Bronce Final y el período orientalizante en Extremadura. (B.P.H. XIV). Madrid, Ministerio de Cultura.

AMMERMAN, A.J. y CAVALLI-SFORZȦ, L.L. (1984): The Neolithic Transition and the Genetics of Populations in Europe. Princeton, Princeton University Press.

AUBET, M. (1994): "Gadir y el comercio Atlántico de metales", Tiro y las colonias fenicias de Occidente. Barcelona, Editorial Crítica, 225-260.

BENDALA, M. (1977): “Notas sobre las estelas decoradas del suroeste y los orígenes de Tartessos", Habis 8:177-205.

(1979-80): "Tres nuevas estelas de guerreros en la provincia de Cordoba", Habis 10:381-390.

(1993): "Componentes de la Cultura Tartéssica", Actas del Congreso Conmemorativo del V Symposium

Internacional de Prehistoria Peninsular. Tartessos 25 años después, 1968-1993. Jerez de la Frontera, Biblioteca de Urbanismo y Cultura (BUC). 255-264.

11. Hay que subrayar que Bendala ha revisado sus teorías adaptándolas a las nuevas corrientes. No obstante sigue defendiendo una hipotética llegada de pobladores griegos al suroeste peninsular, que se vería reflejada por los elementos representados en las estelas -fundamentalmente los carros-, y que habría constituido la base del fenómeno Tartessos: "Hubo pues, una renovación de signo fundamentalmente mediterráneo, propiciada seguramente por inmigraciones de gentes de origen egeo-del amplio mundo micénico en crisis, entre los que es sospechable la presencia de grupos correspondientes a los problemáticos Pueblos del Marresponsables seguramente del componente indoeuropeo que se percibe en el mundo tartésico antiguo" (Bendala 1993:261). Es por esto que el autor clasifica las estelas como un componente definidor de la cultura del Bronce Final Tartésico o Precolonial (entendiendo este término ś́lo con respecto a los fenicios). Afirmaciones que se encuentran lejos de haber sido comprobadas y que personalmente contemplo con una mezcla de reserva y expectación. 
DEAMORES, F. (1993): "La cerámica pintada estilo Carambolo: una revisión necesaria de su cronología", Actas del Congreso Conmemorativo del V Symposium Internacional de Prehistoria Peninsular. Tartessos 25 años después, 1968-1993. Jerez de la Frontera, Biblioteca de Urbanismo y Cultura (BUC). 159-178. FERNÁNDEZ-MIRANDA, M. y OLMOS, R. (1986): Las ruedas de Toya y el origen del carro en la Península Ibérica. (Catálogos y monografías del Museo Nacional, $\mathrm{n}^{\circ}$ 9). Madrid, Ministerio de Cultura.

FRANKFORT, H. (1954): Arte y arquitectura del Oriente Antiguo. Madrid, Cátedra.

GARRIDO, J.P. y ORTA, E. (1978): "Los materiales. Avance de estudio crítico", Excavaciones en la necrópolis de La Joya, Huelva. Madrid, Excavaciones Arqueológicas en España. 167-198.

"Conclusiones", Excavaciones en la necrópolis de La Joya, Huelva. Madrid, Excavaciones Arqueológicas en España. 199-211.

GALÁN, E. (1993): Estelas, paisaje y territorio en el Bronce Final del suroeste de la Península Ibérica. Madrid, Editorial Complutense.

KEEGAN, J. (1995): Historia de la Guerra. Barcelona, Planeta.

LICOLN, B. (1991): Sacerdotes, guerreros y ganado. Madrid, Akal Universitaria.

OLMOS, R. (1989): "Los griegos en Tartesos: una nueva contrastación entre las fuentes arqueológicas y las literarias", en Aubet (coord.) Tartesos, Arqueología Protohistórica del Bajo Guadalquivir. Barcelona, Ausa. 495-520.

PADILLA, A. (1991): “Aproximación a la economía de Asido (Medina Sidonia, Cádiz) y su comarca en época orientalizante”, Habis 22:7-17.

(1994): "Estela del Bronce Final hallada en el término de Ecija (Sevilla)", Spal 3:283-290.

PIGGOTT, S. (1983): The earliest wheeled transport from the Atlantic Coast to the Caspian Sea. Londres, Thames and Hudson.

QUESADA, F. (1997): "De armas de guerra a vehículos al más allá: el carro ligero", La Guerra en la Antigüedad. Madrid, Ministerio de Defensa, 157-164.

REDMAN, C. (1990): Los orígenes de la Civilización. Barcelona, Editorial Crítica.

RENFREW, C. (1990): Arqueología y Lenguaje. La cuestión de los orígenes indoeuropeos. Barcelona, Editorial Crítica.

RUIZ-GÁLVEZ, M. (1995): Ritos de paso y puntos de paso. La Ría de Huelva en el mundo del Bronce Final Europeo. Madrid, Editorial Complutense.

VERNANT, J.P. (1982): "La monarquía micénica", en Marazzi (coord.) La Sociedad Micénica. Madrid, Akal/Universitaria. 192-201. 